\title{
A Predictive Model for Determining Internal Rate Return (Irr) Without Trial and Error
}

\author{
Onuma .E. Onuma \\ Abia State Polytechnic, Aba Nigeria
}

\begin{abstract}
Planners are often confronted with challenges of evaluating proposed capital projects.
The most popular tools are, inter alia

1 Net present value $(\mathrm{NPV})$

2 Benefit/ cost ratio and

3 Internal Rate of return (IRR)

While the first two are straight forwardly determinable IRR on the other hand, requires a trial and error measures. Based on current literature. This is not only challenging in time consumption but presents enormous obstacle for financial advisors during brief sessions with the un-informed Business owners.

The foretasted elicits is a need to develop a straight forward model to approximate IRR without the "TRIAL AND ERROR" Routine

Methodology: The employment of ratio analysis and mathematical logic based on inductive reasoning determined that relationships exist among cost of capital, Benefit/cost ratio and IRR subsequently an Illustrative example on a capital project proved that the model espoused here in is useful.
\end{abstract}

Keywords: Cost Of Capital, Benefit/ Cost Ratio, Npv, Dcf

\section{Introduction}

1.1 Businesses are often challenged to make capital budget decisions. Such decisions cover cost of project, choice among competing project under capital rationing situations etal

1.2 Also, Time is or essence as belated information is as good as no information. Also time value of money must be taken into cognizance in that there should be discounted cash/ flows (or or a terminal or value equation to are those the popular loob for project approval are

(1) Net present value

(2) Benefit/ cost ratio

(3) Internal rate of returns (IRR)

Amongst these, IRR is the most sophisticated, but it is fraught with time consuming technique of "Trial and Error" either by Table or by computation model to obtain IRR study aim at finding to predictive model without Trial and Error routine.

\section{Literature Review}

2.1 C.T. Horngren et al $(2009 ; 763)$ aptly defined IRR as the discount rate at which an investment's Net present value of all expected cash in flows equal the Net present value of al expected cash out flows That is, the IRR is the discount rate that makes NPV $\$ O$ ” They further observed that apart from using computers, trial and error method is used for computing IRR in financial management.

2.2 Brockington, R (1990:110) in financial management holds that "Trial and Error method is utilized for calculating the internal rate of returns.

2.3 Drury C (1992:365) defines internal rate of returns thus:

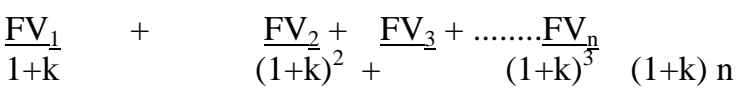

He also holds therein that "IRR can be found by trial and error by using a number of discount factors until NPV equals Zero"

2.4 Ihedioha K.E (2003: 279) also uses and Trial and Error to derive IRR.

2.5 Ashton, Hopper and Scapens (1995:193-194,199) addresses the concept of modified Internal rate of return (MIRR) aimed of mitigating the draw -backs of IRR in traditural mode.

2.6 For MIRR Drury (1992:568) suggests that it is the compounded rate of return that when applied to the initial outlay accumulates to the terminal valve; namely

2.6.1.Terminal value is the forward compounding of all cash flows at the COST OF CAPTIAL to project end date. 
2.6.2 Ascertaining (through Trial and Error) the rate of interest that equates the Terminal value with the initial cost (also compounded).

2.6.3 From the foregoing extant literature "Trial and Error" is utilised whether the Traditional IRR or MIRR mode is in play. Therefore, this study utilised the traditional IRR techniques, for simplicity. Thus it seeks to go around the "Trial and Error" approach and derive a straight predictive model.

4.1 Definition of relevant terms

\section{Illustration}

Cost of capital $(\mathrm{K})=$ The rate of charge on capital employed by the providesls

DCF - Discounted cash flow: The discounted value of future cash returns on today's basis

$\mathrm{NP} . \mathrm{V}=$ Net present value $=$ Excess of Discounted returns over last cost of investment

Discount rate: The rate of converting future returns to present value it is usually equal to cost of capital

\section{Benefit ratio: NPV}

Average lost of Investment

Cost ratio $=$

$$
1-\left\{\begin{array}{l}
\mathrm{NPV} \\
\text { Average }
\end{array}\right\} \text { cost }=\text { complement of Benefit ratio }
$$

\section{Adjusted cost of capital $=\underline{K}$}

\section{1- NPV/ Average cost}

Super ltd has the following data on a capital project. Cost of capital 20\%, initial investment outlay N40,000

Projected Returns

\begin{tabular}{ll} 
Year & \multicolumn{1}{c}{ Cash } \\
& \multicolumn{1}{c}{$\quad$ A } \\
0 & $(40,000)$ \\
1 & 10,000 \\
2 & 15,000 \\
3 & 20,000 \\
4 & 25,000
\end{tabular}

Required

1 The IRR using Trial and Error and interpolation method

2 IRR using this author's predictive model.

4.1 Suggested solution by trial \& Error

$\begin{array}{llllll}\text { Year } & \text { Cash flow } & \text { PVF(20\%) } & \text { DCF (20\%) } & \text { PVF }(26 \% & \text { DCF (26\%) } \\ 0 & (40,000) & 1.00 & (40000) & 1.00 & (40000) \\ 1 & 10000 & 0.833 & 8330 & 0.794 & 7940 \\ 2 & 15000 & 0.694 & 10410 & 0.629 & 9435 \\ 3 & 20000 & 0.578 & 11560 & 0.499 & 9980 \\ 4 & 25000 & 0.487 & 12000 & 0.397 & 9925 \\ & & \text { NPV/+(-) } & & 2350 & (2720)\end{array}$

Applying the traditional IRR model by "Trial and Error" and interpolation 


$$
\begin{aligned}
& \text { IRR }=K+\left\{\frac{N P V_{1}}{N P V_{1}}+N P V_{2}\right\} \times K_{2}-K_{1} \\
& \text { Or K- }\left\{\begin{array}{l}
\mathrm{NPV}_{2} \\
N P V_{1}+\left(N P V_{2}\right.
\end{array}\right\} \times\left(K_{2}-K_{1}\right) \\
& \text { IRR }=20+\left\{\begin{array}{l}
2350 \\
2350+2720
\end{array}\right\} \times 26-20\left\{\begin{array}{c}
2350 \times 6 \\
5070
\end{array}\right\}=22.78
\end{aligned}
$$

Or

$26-$

$$
\frac{2720}{(2720)}+\left\{\begin{array}{l}
2350 \\
2720
\end{array}\right\} \begin{aligned}
& x 26-20 \\
& +2350
\end{aligned}=26-\left\{\frac{2720}{5070}\right\} \times 6=22.78
$$

5.1 Mathematical Justification

\section{The Irr Predictive Model}

Returns less cost $=$ Benefit

Returns $\%$ of less cost $\%=$ Benefit $\%$

Let Return $=\mathrm{R}$, Cost of capital $=\mathrm{K}$ and Benefit ratio

$b=$ NPV

Average cost if there is one investment(s) then

$$
\begin{aligned}
& \text { Average }=\frac{\mathrm{O}+\mathrm{C}}{2}+\mathrm{C} \\
& \mathrm{R}=\mathrm{k}+\mathrm{b}=\mathrm{k}+\frac{\mathrm{NPV}}{1 / 2 \mathrm{C}}
\end{aligned}
$$

Thus the adjusted figure becomes:

$\mathrm{K}_{\mathrm{O}}=\underline{\mathrm{K}}_{1} \underline{\mathrm{O}}$

At $\mathrm{IRR}=\mathrm{NPV}=0$ and Ko is adjusted by the complement of Benefit ratio:

1- $\quad \underline{\text { NPV }}$

$1 / 2 \mathrm{C}$

Thus the adjusted figure becomes

$$
\left\{\frac{N P V}{1 / 2 C}\right\}
$$

Recall from $\mathrm{Eg}(1)$

Gross returns $=$ Adjusted cost + Benefit $=$ minimum expected returns rate

$$
I R R=\left\{\frac{\mathrm{K}_{0}}{1-\underline{N P V}} \underset{1 / 2 C}{12}\right\} \pm\left\{\frac{N P V}{1 / 2 C}\right\}
$$

Generally

In order to accommodate both positive and Negative NPV SCENARIOS

$\mathrm{IRR}=\underline{\mathrm{Ko}}$

$$
\frac{1 \pm N P V}{1 / 2 \mathrm{C}} \quad \pm \quad \frac{\mathrm{NPV}}{1 / 2 \mathrm{C}}
$$

Where $1 / 2 \mathrm{C}=$ Average Investment 
NPV $=$ Net Present Valve

$\mathrm{Ko}=$ Cost of Capital

For The Application Of The Irr Predictive Model

Step 1 Compute the Benefit ratio = NPV

Step 2 Compote the complement of step

$1=1 \frac{\mathrm{NPV}}{1 / 2 \mathrm{C}}=$ cost Ratio

Step3 Divide outcome figure of step 2 into the cost of capital to obtain the adjusted cost of capital deemed intrinsic.

Step 4 Add/ (subtract) figure of step 1 and figure of step 3 (summation)to obtain total Return rate applicable thereof.

This figure is the minimum expected rate of return $=$ I.R.R

with $\pm 1 \%$ error.

\subsection{SCENARIO 1}

Positive NPV, cost of capital $20 \%$, NPV $=2350$

Step1 $\quad \underline{\text { NPV }} \quad \underset{1 / 2}{=} \underline{2350}=0.1175$

Step2 Complement $=1-0.1175=0.8828$

Step3 $\underline{20 \%} \quad=22.662$ (adjusted cost of capital) .8825

Step 4 Add resultant of step 1 and step $3=0.1175+22.662$

22.737 This is IRR approximately!!.

6.2 SCENARIO II

NEGATIVE NPV; $\quad$ Cost of capital $=26 \%$, NPV $=(2720)$

Step 1 Computed Benefit

$$
\begin{gathered}
\text { ratio }=(\underline{2720)} \quad=(0 ., 36) \\
\text { Average Cost }
\end{gathered}
$$

Step 2 Since it is a loss (Negative NPV)

Complement $=1(0.136)$

$$
1.136
$$

Step 3 Dividing cost of capital by complement $=\underline{26}=22.887$

Step 4 Since it is a negative NPV and

Benefit ratio, step 1+ step 3 becomes

$22.887-0.136=22.351$

IRR = Again this is IRR approximately !!

\section{Summary And Conclusion}

7.1 IRR is a key tool in project appraisal it uses time consuming Trial and Error method.

This research study was aimed at deriving an approximate approach that avoids Trial and Error but Straightforwardly predicts IRR. The model is based on mathematical logic

$$
\begin{aligned}
& \text { Returns = Cost }+ \text { Benefit } \\
& I R R=\text { Adjusted cost }+ \text { Benefit }
\end{aligned}
$$

The adjusted of capital cost $=\underline{\mathrm{Ko}}$

Where Ko is the original cost of capital

$$
\text { complement of Benefit ratio }
$$

$\mathrm{IRR}=\underline{\mathrm{K}} \quad+\underline{\mathrm{NPV}}$ 
1- NPV $\quad 1 / 2 \mathrm{C}$

$1 / 2 \mathrm{C}$

\subsection{SIGNIFICANCE}

The Significance is that planners work is made easier

Computer application programmes could be more early created based on the prediction model espoused herein.

\subsection{CONCLUDING REMARK}

In view of the foregoing the research is useful for capital project planner and advisory services providers.

\section{References}

In numerical sequence)

[1]. Horngren C.T.et al (2009:763) Cost Accounting -A Managerial Emphasis (13 ${ }^{\text {th }}$ ed) Pearson \& Prentice Hall London (3)

[2]. Brockington R. (1990:170) ELBS \& DP Publications London (3).

[3]. Drury C (1992:365) Chapman \& Hall London (3)

[4]. Ihedioha K.E (2003:279) Break through Books Aba Nigeria (4)

[5]. Ashton D et al (1995:193-194, 199) Prentice Hall London (4)

[6]. Drury C (1992: 368) Chapman \& Hall London (4) 